\title{
La "fuga" de Don Proti (cuento) o La ubicación de los laicos de puesto nombrado en los actos oficiales de la Iglesia Católica
}

The "flight" of Mr. Proti (story) or Places allocated to the lay people appointed by the Holy See for the official events of the Catholic Church

\author{
M.D. Martínez Cazalla ${ }^{1}$ \\ Universidad de Sevilla/Université Lille-3 \\ madomartinezcazalla@gmail.com
}

Recepción:01/05/16 Revisión: 16/05/16 Aceptación: 16/05/16 Publicación: 01/06/16

http:// (página web de inclusión del artículo)

\section{Resumen (máximo 300 palabras)}

Dado que el protocolo tiene por objeto el ordenar personas, documentos, símbolos, espacios y tiempos, para así poder cumplir con su objetivo, comunicar, va de suyo que si se ordena de manera inadecuada a los deseos de comunicación, lo que el receptor recibirá no será lo que se ha querido comunicar. Así pues, la ponencia tendrá por objetivo, dentro del marco del protocolo eclesiástico, mostrar la importancia que tiene el escoger una u otra forma a la hora de ordenar/ubicar a los laicos de puesto nombrado en los actos oficiales de la Iglesia Católica. Es decir, '¿Cómo se ordenan y por qué?’ y '¿Qué está comunicando dicha ordenación?'. Será una invitación a reflexionar juntos sobre '¿dónde sentar a un laico de puesto nombrado en un acto oficial de la Iglesia Católica?', apoyándonos en todo momento tanto en la tradición, usos y costumbres, como en textos oficiales de la Iglesia Católica.

El "cuento" (La "fuga" de Don Proti) será el estilo literario escogido para presentar las posibles ordenaciones y lo que respectivamente están comunicando. Éste permite

\footnotetext{
${ }^{1}$ Licenciada en Filosofía. Máster en Relaciones Internacionales, sección: Diplomacia y Resolución de Conflictos y Máster en Protocolo.

Doctoranda en Filosofía, Lógica y Filosofía de la Ciencia. Departamento de Filosofía, Lógica y Filosofía de la Ciencia. Universidad de Sevilla, España / Centre de Recherche: Savoirs, Textes et Langage (STL). École Doctorale Sciences de 1'Homme et de la Société. Université de Lille-3, France. Trabajo en la creación de diálogos lógicos para establecer protocolos para negociaciones, esto significa: resolver conflictos a partir de estructuras lingüísticas básicas (conjuntivas; disyuntivas; condicionales) ordenadas bajo la forma de diálogo, como si se tratase de un sistema cognitivo que "entiende" el lenguaje natural y donde se produce un permanente feed-back entre ambos. Para ello analizo y utilizo el comportamiento de los lenguajes cifrados y de los patrones neurolingüísticos.
} 
crear una ficción sobre un supuesto acto posible y plausible, teniendo la ventaja de poder expresarse con mayor libertad sin por ello herir sensibilidades. Asimismo, se tratará de un cuento abierto, donde serán propuestos tres posibles, y no únicos, finales, dejando al lector la libertad de escoger el que le pareciese más acertado y/o el que más le pudiera complacer así como la de pensar a partir de lo presentado otras variaciones y/o permutaciones posibles.

Palabras clave: Protocolo Eclesiástico; Laicos de puesto nombrado; Actos oficiales de la Iglesia Católica; Lumen Gentium; Código de Derecho Canónico; Magisterio de la Iglesia.

\section{Abstract (maximun 300 words)}

The object of the protocol is to order persons, documents, symbols, places and moments to achieve its objective: to communicate. It is evident that if we do not order in accordance with our wishes of communication, what the recipient will receive will not be what we wanted to communicate. Therefore, this presentation, included in the framework of the ecclesiastical protocol, has as objective to show how important is to choose the placement of the lay people appointed by the Holy See for the official events of the Catholic Church. In other words, 'How to order them and why?' and 'What is this order saying?' This presentation is an invitation to think together about 'where do we place the lay people appointed by the Holy See for an official event of the Catholic Church?' We should always base our answer on the tradition and customs and, on the official texts of the Catholic Church.

We have chosen the story -The "flight" of Mr. Proti- as the style to show the possible orders and what each one is saying. We have opted for this style because the story allows for creating a fiction about a possible and admissible act. Besides stories permits more freedom of expression without offending sensibilities. This is an open story, where three possible ends are proposed, but there may be more. The reader is free to choose the one he thinks is better and/or he enjoys the most. Still he remains free for thinking other possible variations and/or permutations.

Keywords: Ecclesiastical Protocol; Lay people appointed by the Holy See; Official events of the Catholic Church; Canon Law Code; Church's Magisterium

\section{Sumario}

1. Introducción

2. Desarrollo

3. Conclusiones

4. Bibliografía

\section{Summary}

1. Introduction

2. Exposition

3. Conclusion

4. Bibliography 


\section{INTRODUCCIÓN}

Bienvenidos sean todos aquéllos a quienes apasiona pensar lo todavía no-pensado; aquéllos a quienes la pasión por lo todavía no-conocido les puede más que el miedo al mayor de los ridículos intelectuales, y con temor y temblor deciden en él adentrarse.

Por todos es sabido que el protocolo tiene por objeto: el ordenar personas, documentos, símbolos, espacios y tiempos, para así poder cumplir con su objetivo: comunicar. De modo que si se ordena de manera inadecuada a los deseos de comunicación, lo que el receptor recibirá no será lo que se ha querido comunicar. Así pues, la ponencia tendrá por objetivo, dentro del marco del protocolo eclesiástico, mostrar la importancia que tiene el escoger una $u$ otra forma a la hora de ordenar/ubicar a los laicos de puesto nombrado en los actos oficiales de la Iglesia Católica. Es decir, ‘¿Cómo se ordenan y por qué?’ -objeto de la investigación- y ‘¿Qué está comunicando dicha ordenación?'-objetivo de la investigación-. Será una invitación a reflexionar juntos sobre '¿dónde sentar a un laico de puesto nombrado en un acto oficial de la Iglesia Católica?'. En todo momento nos apoyaremos tanto en la tradición, usos y costumbres, como en textos oficiales de la Iglesia Católica, que podríamos dividir en dos pilares: por un lado los documentos del Concilio Vaticano II, destacando como principales para nuestro cometido: la Constitución Dogmática "Lumen Gentium"; el Decreto "Ad Gentes Divinitus" y el Decreto "Christus Dominus" y siendo el otro pilar del cuerpo teórico el Código de Derecho Canónico de 1983 (en concreto aquellos artículos que nos ayudarán a dilucidar la primacía o no primacía del 'derecho de orden' frente al 'derecho de jurisdicción' y viceversa) y la nueva edición de El Magisterio de la Iglesia del año 2000.

El "cuento" (La "fuga" de Don Proti) es el estilo literario escogido para presentar las posibles ordenaciones y lo que respectivamente están comunicando. Éste permite crear una ficción sobre un supuesto acto posible y plausible, teniendo la ventaja de permitir mayor libertad en la expresión sin por ello herir sensibilidades. Asimismo, se tratará de un cuento abierto, donde serán propuestos tres posibles, y no únicos, finales, dejando al lector la libertad de escoger el que le pareciese más acertado y/o el que más le pudiera complacer así como la de pensar a partir de lo presentado otras 
variaciones y/o permutaciones posibles. De ahí que la presente investigación no contenga un apartado de "conclusiones". A ustedes el sacarlas.

Por otro lado, respecto a lo que con lo estrictamente mecánico tiene que ver, es decir, ubicar a cada uno de los participantes en un asiento, ya que de un acto eclesiástico oficial se trata, se tomará como referencia lo que sobre protocolo eclesiástico hay ya establecido y atendiendo a ello se ha realizado el documento del orden de precedencias de las diócesis españolas. Éste nos será imprescindible en lo que al establecimiento de las precedencias de los laicos de puesto nombrado se refiera, ya que éstas vendrán determinadas por la que tenga la autoridad eclesiástica bajo la cual se encuentre la jurisdicción de sus puestos. Para la posible solución de cuestiones colaterales en el tema de ubicación de todos los laicos presentes (de puesto nombrado, autoridades, simples fieles), no habiendo por el momento un protocolo determinado para ello, se utilizará como referente el Real Decreto 2099/1983 de Ordenamiento General de Precedencias en el Estado.

En cuanto a los datos cuantitativos provienen de haber contactado personalmente una a una, cada una de las setenta diócesis en las que se encuentra divida España. Gracias a la gran colaboración de algo más del cincuenta por ciento de ellas ha sido posible poder trabajar con valores bastante cercanos a los reales. Ustedes quizá se pregunten en este punto: '¿cómo es posible pensar que los valores totales son bastante cercanos a la realidad si sólo conocemos algo más del cincuenta por ciento?' Bien, les revelaremos el "secreto". Un número importante de las diócesis que han colaborado han sido poco estrictas en su respuesta a la pregunta: '¿Cuántos laicos de puesto nombrado hay actualmente en su Curia?'. Al menos la mitad ha dado por respuesta el número total de laicos en la Curia, no siendo todos ellos de puesto nombrado en sentido estricto, es decir, que ocupen cargo en el equipo de gobierno de la diócesis. Esto, que al principio resultaba un poco engorroso pues requería comparar los organigramas de cada una de las curias con la respuesta obtenida, al final ha resultado ser ventajoso, ya que ha permitido utilizar el supuesto "exceso" como cantidad representativa para el total de laicos de puesto nombrado en las diócesis que decidieron no colaborar, pues al comparar este "exceso" con los que según el organigrama de la Curia de las diócesis no colaboradoras podrían ser laicos, el número 
encajaba bastante bien. Así que entre una cosa y otra se ha podido obtener un número suficientemente real. De igual modo se ha procedido con las respuestas dadas a la segunda pregunta hecha a las diócesis españolas: '¿Cuántos de esos laicos están casados?'. Como ven, no se ha escatimado un ápice en que el cuento, aun siendo totalmente una ficción en tanto que método discursivo, fuese de lo más real y plausible tanto en el planteamiento como en los datos que en él se manejan. Estos datos han sido reducidos (para resolver la escasez de aforo real) en un cincuenta/sesenta por ciento de modo proporcional (mismo rasero para todos los tipos de miembros -sacerdotes, religiosos/as y laicos- de la Curia de las diferentes diócesis). Como la pretensión nunca ha sido hacer un trabajo de estadística, estos datos no aparecerán de manera explícita en ningún momento, pero sí se quería informar al lector sobre cómo se han obtenido y qué tratamiento se les ha dado, pues los asientos destinados a unos y a otros no son fruto del antojo, como tampoco lo serán los reservados para las "Autoridades Civiles y Militares" ni para los llamados "Otro tipo de invitados de renombre" (ej: representantes de la nobleza española, Hermano Mayor de la Hermandad XX, personalidades de los diferentes campos de la ciencia y de la cultura, etc.), ambas categorías aparecerán como un único bloque en sí mismas y sin detalle porque no son ellos el objeto de esta investigación. Por último, el bloque "Otros laicos" que aparece en la Figura B. y en la Figura C. no responde a ningún número concreto, ni implícito ni explícito, simplemente fueron los "sobrantes" en sentido positivo, es decir, se aplicaron reducciones proporcionales en los otros grupos para que quedase espacio para ellos, pues aunque se trata de Acto Oficial Público Restringido, se entiende que la restricción viene impuesta por el aforo pero que en tanto oficio religioso público la Iglesia debe prever un mínimo de sitios para los simples fieles.

La fecha de corte en lo que a los datos cuantitativos se refiere así como en lo que afecta al orden de precedencias de las diócesis ha sido el día 3 de abril de 2016.

En lo que al soporte técnico se refiere, la realización de todos los planos y demás grafías que van a ver están hechos a estricta escala y han sido realizados para la ocasión de modo quasi artesanal a partir de una primera imagen de la planta de la Catedral de Santa María la Real de la Almudena y un mínimo de datos (dimensiones y 
número real de bancos y sillones) sobre la misma. Se escogió dicha Catedral porque al no ser gótica (el coro no está situado en la nave central) daba más y mejores opciones para las posibles distribuciones, cosa muy de agradecer dado el nivel de dificultad que ya entrañaba la propia investigación a causa del tema escogido. El programa utilizado para la ejecución de dichos planos ha sido el Adobe Illustrator CC 2014 y Dña. Laura Hidalgo García ha sido la encargada de la materialización de los mismos, no habiendo palabras suficientes para agradecerle el tiempo, el esmero y la dedicación. Sin su valiosísima ayuda las representaciones gráficas no hubieran sido posibles, por no decir, inimaginables.

Por último, sólo unas breves palabras sobre el último apartado del cuento: Referencias de textos oficiales de apoyo para la Figura y el Comunicado B. y para la Figura y el Comunicado $C$. Se podría definir este apartado como una especie de anexo que acompaña los Comunicados de Prensa correspondientes a las Figuras B. y C. La decisión de recoger las referencias de textos oficiales en un solo apartado y no irlos ofreciendo poco a poco ha sido tomada por dos motivos (serán introducidos bajo guiones y no numerados, porque ambos nos parecen de igual importancia):

- Al tratarse de un cuento, el llenarlo de citas y/o notas a pie de página resulta inoportuno e impropio, de hecho sólo aparecerán las imprescindibles. Mismo motivo para el caso de los Comunicados de Prensa, de ahí que junto a ellos se ofrezca un documento anejo con las referencias de textos oficiales que los apoyan.

- Como todas las argumentaciones que van a ser utilizadas quedan entrelazadas y sirven al tiempo de apoyo tanto al Comunicado de Prensa de la Figura B. como al de la Figura C. Nos pareció prudente recogerlas todas juntas, y ordenadas convenientemente presentarlas en un documento único que se prestara a poder ser entregado a modo de anexo para dichos comunicados. En tanto que concebido como complemento anejo a los comunicados de prensa será breve, conciso y sin pretensión alguna de abrir discusiones teológicas y/o canonistas. Simplemente servirá de apoyo explicativo, orientado a complementar la comunicación; a que los porqués de una ordenación u otra 
frente a la propuesta en la Figura A. tengan razón de ser, al menos, de ser pensados. Y que la prensa y por ende cualquier lector/espectador medio pueda entenderlos, los comparta o no.

Invitados quedan a disfrutar con el cuento les vamos a contar.

\section{CUENTO: LA “FUGA" DE DON PROTI}

El concepto eje de este cuento será el de "Pueblo de Dios":

- Histórico: El uso por tradición y costumbre de llamar al conjunto de los laicos "Pueblo de Dios" data prácticamente de los inicios de la Iglesia, quedando claramente recogido en su Magisterio: "D-2300 Nota: (2) Cf. Concilio de Trento, Sec. 23, cap. 4 [v.960]. (...) Una cosa, sin embargo, creemos oportuno recordar y es que el sacerdote solamente representa al pueblo porque representa la persona de Nuestro Señor Jesucristo en cuanto es Cabeza de todos los miembros y por ellos, se ofrece a sí mismo, y que se acerca, por ende, al altar como ministro de Cristo, inferior ciertamente a Cristo, pero superior al pueblo (...).” (DENZINGER, 1963).

- Año 1964: En el Concilio Vaticano II queda clarificado que el Pueblo de Dios son todos los miembros de la Iglesia, es decir, todos los bautizados: "32. (...) Por tanto, el Pueblo de Dios, por Él elegido, es uno: "un Señor, una fe, un bautismo» (Ef 4,5). Es común la dignidad de los miembros, que deriva de su regeneración en Cristo; común la gracia de la filiación; común la llamada a la perfección: una sola salvación, única la esperanza e indivisa la caridad. No hay, de consiguiente, en Cristo y en la Iglesia ninguna desigualdad por razón de la raza o de la nacionalidad, de la condición social o del sexo, porque «no hay judio ni griego, no hay siervo o libre, no hay varón ni mujer. Pues todos vosotros sois "uno" en Cristo Jesús» (Ga 3,28 gr.; cf. Col 3,11)." Constitución Dogmática "Lumen Gentium”. 
- Año 1983: “(...) Por lo cual, el Código, no sólo por su contenido, sino también ya desde su primer comienzo, demuestra el espíritu de este Concilio, en cuyos documentos la Iglesia, universal «sacramento de salvación» (cf. Lumen Gentium 9 a 48), es presentada como Pueblo de Dios y su constitución jerárquica aparece fundada sobre el Colegio de los Obispos juntamente con su Cabeza." (JUAN PABLO II, Papa (1983): Constitución Apostólica: "Sacrae Disciplinae Leges", p. 3. En: Código de Derecho Canónico de 1983). Quedando explicitado en el Canon 204, párrafo $1^{\circ}$ de dicho Código: "C.204 § 1. Son fieles cristianos quienes, incorporados a Cristo por el bautismo, se integran en el pueblo de Dios, y hechos partícipes a su modo por esta razón de la función sacerdotal, profética y real de Cristo, cada uno según su propia condición, son llamados a desempeñar la misión que Dios encomendó cumplir a la Iglesia en el mundo."

- Año 2000: Nueva edición del Magisterio de la Iglesia (DENZINGER, H. y HÜNERMAN, P. (2000) El Magisterio de la Iglesia. Barcelona, Herder. Versión castellana de la $38^{\mathrm{a}}$ edición alemana) donde ya no aparece la nota que acabamos de referir.

- Año 2016: Érase una vez una luminosa tarde de otoño, los rayos del sol que entraban por un inmenso ventanal templaban la mesa de Don Proti.

Don Proti era el Jefe de Protocolo de la Conferencia Episcopal Española (CEE). Llevaba en el puesto treinta largos años, había empezado en su juventud como ayudante del anterior Jefe de Protocolo y tras la jubilación del mismo, él había asumido el cargo. En estos días, Don Proti, contemplaba este otoño de manera especial, el día de su jubilación se acercaba. Gustaba de mirar directamente al sol tras el ventanal, como si de una afrenta se tratase, y en este último tiempo casi que le retaba:

- ¡Eh sol!, ¿te quedará todavía un último destello que ponga el broche de oro a mi carrera?

Lo que Don Proti no podía ni imaginar es que ese "destello" iba a llegar en forma de llamada telefónica justo unos minutos más tarde. 
- Don Proti, (se escucha la voz de Faustina, su secretaria), le llama el Presidente de la Conferencia Episcopal. Le paso la llamada.

- Sí Excelencia, dígame.

- Mire Don Proti, quería ser yo mismo quien le pusiera en el conocimiento de su próxima encomienda. El Presidente de la COMisión de los Episcopados de la Comunidad Europea (COMECE) acaba de anunciarnos su venida en visita oficial a nuestra Conferencia Episcopal el mes próximo. Disculpe que se le informe con tan poco adelanto, pero no esperábamos su visita hasta dentro de unos seis meses, al parecer ha tenido que adelantarla. Don Proti, ni decir tiene la importancia de que todo salga a la perfección. Es sumamente importante que cuidemos los más mínimos detalles durante toda su visita. Lo más relevante será el recibimiento oficial, que si a usted le parece, por lo que al protocolo se refiere, hemos pensado que podría ser con la celebración de una misa solemne en la Catedral de la Almudena, ya que al estar en Madrid y tener unas excelentes posibilidades de aforo nos permite poder dar cabida a todos a los que habría que invitar para tal evento.

- Muy bien Excelencia, pues me pongo a ello, y no se preocupe por la premura que todo estará listo en su momento. Quede tranquilo, que trataré el encargo con el cariño y la dedicación que siempre he puesto al servicio de esta casa, más aun pensando que quizá sea el último evento de empaque que tenga la ocasión de realizar durante mi carrera profesional.

- Bueno, bueno, no se me ponga melodramático y manos a la obra que espero me presente en un par de días el boceto con las ubicaciones.

- Desde luego, Excelencia, quede tranquilo y cuente con ello, dentro de un par de días, si no antes, lo tendrá sobre la mesa de su despacho.

- Pues lo dicho, Don Proti, y qué el Señor le ilumine.

- Gracias, Excelencia. Buenas tardes. 
- iFaustina, Faustina! (se escucha a Don Proti casi gritar de emoción contenida, parecía que el sol en el ocaso de su vida profesional había decidido aceptar el "reto") Venga enseguida que tenemos mucho trabajo.

- Dígame, ¿qué se le ofrece?

- Pues bien, le pongo en antecedentes: el Presidente de la COMECE viene en visita oficial a la Conferencia Episcopal Española el mes próximo. Nuestra Conferencia quiere recibirle, como es natural, con la celebración de una misa solemne en la Catedral de la Almudena. Su Excelencia quiere el boceto, con la ubicación de los invitados al acto, en su despacho a lo más tardar en un par de días.

- ¿Y no son muchos los invitados que hay que colocar para tan poco tiempo? ¿Sólo en un par de días quiere que tengamos hecho algo bastante definitivo?

- Bueno, Faustina, no se me agobie. Más o menos son los de siempre: el anfitrión; los invitados de honor; las autoridades eclesiásticas; los miembros del Cabildo Catedralicio; los miembros de las Curias de España; las autoridades civiles; otro tipo de invitados de renombre y por último el Pueblo de Dios. Así que por favor, sea tan amable de sacarme una copia impresa del plano de planta con asientos de la Catedral de la Almudena.

- En seguida, Don Proti.

Y dicho y hecho, Faustina diligente le entregó a Don Proti una copia de la planta de la Catedral de la Almudena con los asientos dibujados. Y retirándose de nuevo a su despacho empezó a darle vueltas en su cabecita a la ordenación que éste le había comentado minutos antes. Para Faustina, mujer sin grandes estudios pero estupenda secretaría, aunque nunca se le había ocurrido poner en tela de juicio lo que Don Proti le mandaba o sugería, esta vez no acababa de ver claro que las ordenaciones fueran las más adecuadas. Tras dudar durante largo rato sobre si decirle algo al respecto se decidió a entrar de nuevo en el despacho de Don Proti. Al verla, éste le dijo: 
- Estupendo Faustina, parece que usted me lee el pensamiento. Pensaba llamarla en este momento para decirle que el boceto de ubicaciones está listo y que ya puede hacérselo llegar a su Excelencia, el Señor Presidente. (Véase Figura A.).

- Bueno, si me lo permite, Don Proti, yo quisiera atreverme a hacerle una pequeña observación, y como si no he entendido mal, su Excelencia le ha dado un par de días para la presentación del boceto de las ordenaciones, me gustaría permitirme el sugerirle la propuesta de otras opciones como también posibles.

- ¿Qué está usted queriendo decir con eso de "otras opciones también posibles"?

- Pues verá, sin ánimo de poner en duda su buen trabajo, he estado dándole vueltas al hecho de que en la mayoría de las Curias españolas actuales hay laicos de puesto nombrado, es decir, son miembros del equipo de gobierno de la diócesis. De hecho, también los hay aquí, en la Conferencia Episcopal Española.

- Sí, claro. ¿Y qué me está queriendo decir con ello? Disculpe, pero no la entiendo. Hace ya muchos años que esto así, de hecho esto empezó progresivamente después del Concilio Vaticano II y nosotros seguimos ordenando como siempre se ha hecho y todo el mundo está encantado.

- Bien, es que se me ocurría que quizá como desde hace ya algunos años se viene celebrando el cincuentenario del Concilio Vaticano II y por tanto la Constitución Dogmática "Lumen Gentium" cuenta ya con más de cincuenta años y a mi parecer, si bien he entendido lo dicho en las conferencias a las que he tenido la oportunidad de asistir, fue la base de la apertura del acceso a puestos nombrados al laicado... Pues eso, que me parecía, que quizá llega la hora de que los laicos de puesto nombrado tengan un sitio claramente determinado en la ordenación de los invitados a los actos oficiales de la Iglesia Católica. 
- Mire Faustina, llevo más de treinta años en el cargo de Jefe de Protocolo de esta casa. Cuando llegué a él, el Concilio Vaticano II ya estaba en vigor, por tanto había ya laicos de puesto nombrado tanto en esta casa como en bastantes de nuestras diócesis. Y a pesar de todo ello, seguimos ordenando como siempre. Los laicos con los laicos, es decir, se les priorizará a la hora del reparto de invitaciones para el Pueblo de Dios pero se sentarán sin orden preestablecido en la zona dispuesta para los mismos.

- Disculpe mi osadía, Don Proti, en ningún momento quise molestarle, sólo fue un pensamiento, sin duda inoportuno y erróneo.

- Sí, sí, no se preocupe, a veces los pensamientos apasionados no nos dejan ver con claridad. Y ahora, hágame el favor de tomar el plano y llevarlo al despacho de su Excelencia.

Faustina se retiró del despacho de Don Proti tomando entre sus manos el plano de ubicaciones en cuestión y simuló salir para llevarlo a su destino: el despacho de su Excelencia. Pero Faustina, que llevaba toda su vida al servicio de Don Proti y le conocía bien, sabía que sus comentarios no iban a caer en saco roto, así que decidió guardar dicho plano bajo llave en el secreter de su propio despacho. Como había dos días de plazo, quiso esperar por si acaso Don Proti decidía cambiar de opinión tras la conversación que acababan de mantener.

Don Proti, por su parte, aunque mantuvo la apariencia de como si nada hubiera pasado, las reflexiones de Faustina dejaron huella en sus pensamientos. Él quería su "broche de oro", y como se atreviese a poner en cuestión lo dado hasta el momento, lo que iba a obtener era una posible jubilación anticipada por despido inmediato. Él sentía que si se permitía realizar lo que Faustina le había insinuado, en cierto modo, iba a desacatar a la autoridad. Temeroso y a la vez interpelado por la sabia reflexión que Faustina le había hecho, decidió pasar la noche en vela y estudiar con atención los documentos del Vaticano II y lo que el Código de Derecho Canónico podría decirle al respecto. 
A la mañana siguiente cuando Faustina regresó de nuevo al despacho, éste le dijo:

- Buenos días Faustina, iQué nadie me moleste hasta nueva orden, no estoy para nadie! ¿Entendido?

- Sí, cómo no, lo que usted mande.

Ese día, Don Proti, lo pasó encerrado en su despacho hasta bien entrada la tarde. A eso de las seis llamó a Faustina.

- Faustina, por favor, tráigame urgente dos copias más impresas de la planta de la Catedral de la Almudena con los asientos dibujados.

- A la orden, Don Proti.

Unos minutos después las dos plantas vacías se encontraban en la mesa de Don Proti. Éste volvió a su encierro, mientras Faustina sentía el regocijo interno de quien ganó una batalla. Ahora sí sabía que Don Proti había reconsiderado su cuestión y que iba a atreverse a pensar al menos uno o dos modos nuevos de ubicación para los laicos de puesto nombrado. Se sentía feliz por haber colaborado a ello, aunque quizá al final no fuese lo que se hiciese, pero al menos su Excelencia tendría la posibilidad de reflexionar también sobre ello y con el tiempo las cosas quizás fueran cambiando. Por otro lado, ya no se sentía temerosa por no haber entregado la primera opción a su Excelencia cuando Don Proti se lo pidió ayer. Ahora, sabía que guardarla había sido una buena decisión, pues conociendo a Don Proti, éste querría entregarlas todas juntas para no dar sensación de falta de unidad y seriedad en su trabajo. Y así fue como una noche más, Faustina abandonó el despacho dejando a Don Proti sumido en la tarea. Aunque en cierto modo se sentía culpable por haberle robado el sueño a Don Proti; por otra parte, su alegría era inmensa: pensar que ella, una humilde secretaría, quizá iba a darle un empujoncito a Iglesia gracias a su osado comentario. Ese regocijo no tenía precio, para ella sólo el hecho de que fuera pensable ya era como haber recibido la medalla de oro a su carrera.

Al día siguiente, cuando de nuevo entró Faustina en su despacho, se escuchó la llamada de Don Proti: 
- Faustina, buenos días. Dos cosas:

1 ¿ ¿Al final entregó usted el primer plano con las ordenaciones a su Excelencia?

2ㅇ ¿Podría ayudarme con la redacción de los comunicados de prensa ${ }^{2}$ ? Me gustaría dejar todo ultimado en esta mañana.

- Pues verá, en lo que se refiere a ayudarle con los comunicados de prensa. Cuente con ello. Con respecto a lo del plano, no sé cómo decirle que no hice exactamente lo que usted me mandó. Es que pensé... que quizá usted iba a reconsiderar mis comentarios y como teníamos dos días... me tomé la libertad de guardarlo bajo llave en mi secreter.

- iEso, no estuvo bien!, pero tengo que reconocerle que para este caso su desobediencia nos va al pelo (Los dos se miran sonrientes, con esa sonrisa alegre y maliciosa de quienes se saben cómplices en el quizá "delito" de intentar reescribir la historia de las precedencias eclesiásticas en los actos oficiales de la Iglesia Católica). (Véase segunda ordenación en la Figura B. y la tercera ordenación en la Figura C.) Bueno pues, manos a la obra.

Fue así como Don Proti, con la ayuda de Faustina, se puso a redactar los comunicados de prensa para cada una de las tres ordenaciones propuestas.

\footnotetext{
${ }^{2}$ Nota aclaratoria: Se los designa como "comunicados de prensa" y no, como "notas de prensa" porque su finalidad es ser emitidos con anterioridad a la ejecución del acto. Por otro lado, añadimos la aclaración explicativa del porqué en ninguno de ellos aparecerá el logotipo de la entidad emisora (en nuestro caso el de la CEE), el motivo no es otro que todavía no son los oficiales, es decir, Don Proti los está creando a modo de borrador para presentarlos adjuntos a las posibles ordenaciones ante el Sr. Presidente de la CEE.
} 
Figura A.

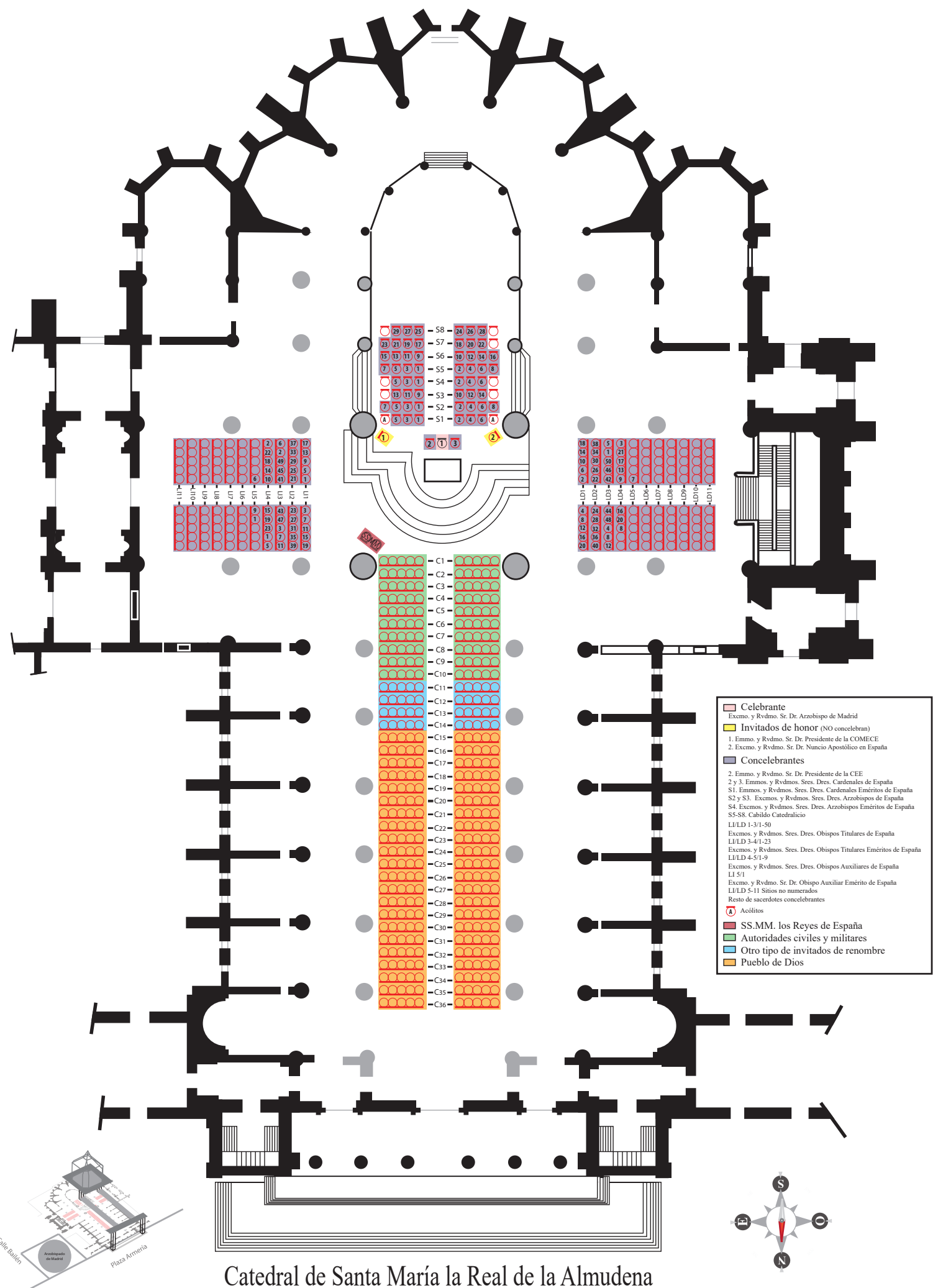


COMUNICADO DE PRENSA PARA LA FIGURA A.

La visita oficial del Presidente de la Comisión de los Episcopados de la Comunidad Europea a la Conferencia Episcopal Española se iniciará con la celebración de una misa solemne en la Iglesia Catedral de Santa María la Real de la Almudena

La CEE acoge la visita oficial del Presidente de la COMECE

La Conferencia Episcopal Española (CEE) tiene el gusto de acoger en visita oficial del $\mathrm{X}$ al $\mathrm{Y}$ del mes próximo al Presidente de la COMisión de los Episcopados de la Comunidad Europea (COMECE), Emmo. y Rvdmo. Sr. Dr. D. XX

El recibimiento oficial tendrá lugar en la Iglesia Catedral de Santa María la Real de la Almudena con la celebración de una misa solemne que contará con la participación de todas las Curias de España.

La CEE recibe la visita oficial del Presidente de la COMECE. El recibimiento oficial tendrá lugar en la Iglesia Catedral de Santa María la Real de la Almudena el próximo día XX del mes YY. La celebración se iniciará a las 18h00. Será presidida por el Obispo de Madrid, Excmo. Y Rvdmo. Sr. Dr. D. XX con la participación de todas las Curias de España y así mismo, contará con la asistencia de SS.MM. los Reyes de España y del Nuncio Apostólico en España. Tras la celebración de la Santa Misa será ofrecido un cóctel de bienvenida en los salones del edificio del Arzobispado de Madrid, situado contiguo al edificio de la Iglesia Catedral.

Como pueden ver en la Figura A. que se les adjunta, la disposición de los participantes será la siguiente y responderá a lo que viene siendo habitual en este tipo de actos:

La celebración será presidida por el Obispo de Madrid, Excmo. y Rvdmo. Sr. Dr. D. XX, en calidad de titular de esta sede obispal, ya que es el obispo del lugar el designado para presidir las celebraciones en su casa, aunque en este caso el anfitrión propiamente no sea él, sino la $\mathrm{CEE}^{3}$. Por tanto, a su derecha (izquierda para el

\footnotetext{
${ }^{3}$ El obispo que se encuentra en su sede episcopal tiene potestad jurídica sobre la misma, por lo tanto es su máxima autoridad, no teniendo porque ceder la presidencia salvo si concurriese con una autoridad superior. No siendo éste el caso, es el obispo quien preside ya que el Presidente de la CEE representa a un órgano colegiado y no a sí mismo.
} 
espectador) y en calidad de concelebrante (al que a efectos puramente prácticos, podríamos llamar "concelebrante primero" pues es el anfitrión del visitante en honor del cual se ha organizado esta celebración) se encontrará el Presidente de la CEE, Emmo. y Rvdmo. Sr. Dr. D. XX y a la izquierda (derecha para el espectador) también como concelebrante se encontrará el otro cardenal no emérito de España: el Emmo. y Rvdmo. Sr. Dr. D. XX. También en la parte principal del presbiterio se encontrarán dos de los tres invitados de honor. No estarán revestidos y por tanto no actuarán como concelebrantes. El Obispo de Madrid tendrá a su derecha (izquierda para el espectador) el principal invitado de honor, el Emmo. y Rvdmo. Sr. Dr. D. XX, Presidente de la COMECE y a su izquierda (derecha para el espectador) otro de los invitados de honor, el Nuncio Apostólico en España, Excmo. y Rvdmo. Sr. Dr. D. XX.

En la parte trasera del presbiterio, zona donde se sitúa el cabildo de esta Iglesia Catedral, se encontrarán sentados, según el orden descrito en la Figura A.: los Emmos. y Rvdmos. Sres. Dres. Cardenales Eméritos de España; los Excmos. y Rvdmos. Sres. Dres. Arzobispos de España; los Excmos. y Rvdmos. Arzobispos Eméritos de España; tras todos ellos, el Cabildo Catedralicio de ésta. Todos revestidos, pues actuarán como concelebrantes en el oficio.

En la parte baja del altar mayor, ya fuera del presbiterio (zona reservada para los ordenados), podrán ver a SS.MM. los Reyes de España como invitados de honor, por tanto, sus sillones se encontrarán en lugar separado y preminente y a la derecha del celebrante (izquierda para el espectador). También en esta zona, ocupando la totalidad de las cuatro hileras de los bancos laterales y todos revestidos, se encontrarán, según la ordenación establecida en la Figura A., el resto de los concelebrantes. Tras los que figuran numerados y nombrados en el cuadro de correlaciones de la Figura A. se situarán los restantes sacerdotes (tanto del clero secular como del regular) miembros de las Curias de España según el orden de precedencias, que se les entregará llegado el día para ayudarles con la identificación. Dicha lista contendrá el nombre y tratamiento, cargo, Curia de procedencia y ubicación exacta para cada uno de ellos. Para ayudarles con la identificación se les incluirá un documento con el orden de precedencias de las diócesis de España, incluida la CEE. 
En la nave central estarán situadas en primer lugar, las autoridades civiles y militares que ocuparán las primeras diez filas de bancos. Tras éstos, los otros invitados de renombre, los cuales ocuparán las siguientes cuatro filas de bancos. De ambos grupos, también llegado el día, se les hará entrega de la lista detallada que contendrá ubicación exacta para cada uno de ellos e incluirá todos los detalles.

Por último, como es costumbre, se situará el Pueblo de Dios, formado por todos aquellos laicos, que habiendo expresado el deseo de asistir al acto, hayan recibido la gracia de ser invitados. Para éstos se reservarán las restantes veintidós filas de bancos de la nave central.

Tras la celebración de la Santa Misa se servirá un cóctel de bienvenida en las dependencias del Arzobispado de Madrid, edificio contiguo a esta Iglesia Catedral. Ubicación que queda detallada en la Figura A. que se les adjunta. 
Figura B.

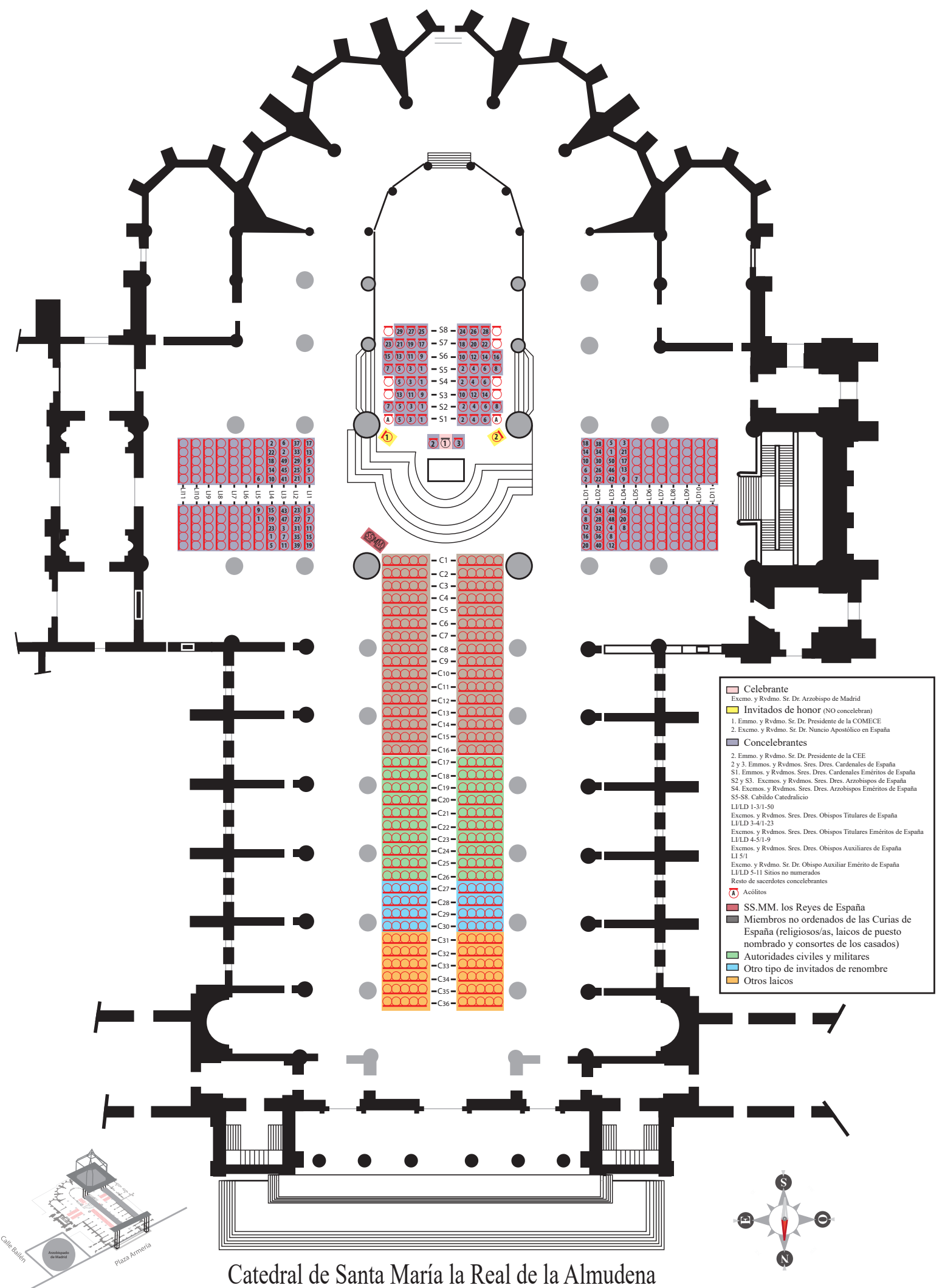


COMUNICADO DE PRENSA PARA LA FIGURA B.

La visita oficial del Presidente de la Comisión de los Episcopados de la Comunidad Europea a la Conferencia Episcopal Española se iniciará con la celebración de una misa solemne en la Iglesia Catedral de Santa María la Real de la Almudena

La CEE acoge la visita oficial del Presidente de la COMECE

La Conferencia Episcopal Española (CEE) tiene el gusto de acoger en visita oficial del $\mathrm{X}$ al $\mathrm{Y}$ del mes próximo al Presidente de la COMisión de los Episcopados de la Comunidad Europea (COMECE), Emmo. y Rvdmo. Sr. Dr. D. XX

El recibimiento oficial tendrá lugar en la Iglesia Catedral de Santa María la Real de la Almudena con la celebración de una misa solemne que contará con la participación de todas las Curias de España.

La CEE recibe la visita oficial del Presidente de la COMECE. El recibimiento oficial tendrá lugar en la Iglesia Catedral de Santa María la Real de la Almudena el próximo día XX del mes YY. La celebración se iniciará a las 18 h00. Será presidida por el Obispo de Madrid, Excmo. Y Rvdmo. Sr. Dr. D. XX con la participación de todas las Curias de España y así mismo, contará con la asistencia de SS.MM. los Reyes de España y del Nuncio Apostólico en España. Tras la celebración de la Santa Misa será ofrecido un cóctel de bienvenida en los salones del edificio del Arzobispado de Madrid, situado contiguo al edificio de la Iglesia Catedral.

Como pueden ver en la Figura B. que se les adjunta, la disposición de los participantes será la siguiente y responderá a la actualidad de los tiempos:

La celebración será presidida por el Obispo de Madrid, Excmo. y Rvdmo. Sr. Dr. D. XX, en calidad de titular de esta sede obispal, ya que es el obispo del lugar el designado para presidir las celebraciones en su casa, aunque en este caso el anfitrión propiamente no sea él, sino la $\mathrm{CEE}^{4}$. Por tanto, a su derecha (izquierda para el

\footnotetext{
${ }^{4}$ El obispo que se encuentra en su sede episcopal tiene potestad jurídica sobre la misma, por lo tanto es su máxima autoridad, no teniendo porque ceder la presidencia salvo si concurriese con una autoridad superior. No siendo éste el caso, es el obispo quien preside ya que el Presidente de la CEE representa a un órgano colegiado y no a sí mismo.
} 
espectador) y en calidad de concelebrante (al que a efectos puramente prácticos, podríamos llamar "concelebrante primero" pues es el anfitrión del visitante en honor del cual se ha organizado esta celebración) se encontrará el Presidente de la CEE, Emmo. y Rvdmo. Sr. Dr. D. XX y a la izquierda (derecha para el espectador) también como concelebrante se encontrará el otro cardenal no emérito de España: el Emmo. y Rvdmo. Sr. Dr. D. XX. También en la parte principal del presbiterio se encontrarán dos de los tres invitados de honor. No estarán revestidos y por tanto no actuarán como concelebrantes. El Obispo de Madrid tendrá a su derecha (izquierda para el espectador) el principal invitado de honor, el Emmo. y Rvdmo. Sr. Dr. D. XX, Presidente de la COMECE y a su izquierda (derecha para el espectador) otro de los invitados de honor, el Nuncio Apostólico en España, Excmo. y Rvdmo. Sr. Dr. D. XX.

En la parte trasera del presbiterio, zona donde se sitúa el cabildo de esta Iglesia Catedral, se encontrarán sentados, según el orden descrito en la Figura B.: los Emmos. y Rvdmos. Sres. Dres. Cardenales Eméritos de España; los Excmos. y Rvdmos. Sres. Dres. Arzobispos de España; los Excmos. y Rvdmos. Arzobispos Eméritos de España; tras todos ellos, el Cabildo Catedralicio de ésta. Todos revestidos, pues actuarán como concelebrantes en el oficio.

En la parte baja del altar mayor, ya fuera del presbiterio (zona reservada para los ordenados), podrán ver a SS.MM. los Reyes de España como invitados de honor, por tanto, sus sillones se encontrarán en lugar separado y preeminente y a la derecha del celebrante (izquierda para el espectador). También en esta zona, ocupando la totalidad de las cuatro hileras de los bancos laterales y todos revestidos, se encontrarán, según la ordenación establecida en la Figura B., el resto de los concelebrantes. Tras los que figuran numerados y nombrados en el cuadro de correlaciones de la Figura B. se situarán los restantes sacerdotes (tanto del clero secular como del regular) miembros de las Curias de España según el orden de precedencias, que se les entregará llegado el día para ayudarles con la identificación. Dicha lista contendrá el nombre y tratamiento, cargo, Curia de procedencia y ubicación exacta para cada uno de ellos. Para ayudarles con la identificación se les incluirá un documento con el orden de precedencias de las diócesis de España, incluida la CEE. 
En la nave central estarán situados en primer lugar, el resto de los miembros de las Curias de España, es decir, todos los no ordenados ya sean religiosos, religiosas o laicos de puesto nombrado ${ }^{5}$, es decir, todas aquellas personas que no habiendo recibido el orden sacerdotal forman parte del equipo de gobierno de una diócesis. Por tanto, sobre todos ellos pesará un mandato que implicará una determinada jurisdicción sobre uno o varios aspectos del gobierno de la diócesis. Aquellos laicos de puesto nombrado que estén casados podrán ser acompañados por sus consortes, situados de manera inmediatamente contigua a su cónyuge ya que al estar "fuera de la zona conocida como presidencia (en el interior de una iglesia la zona de presidencia es la zona de influencia del altar mayor: el presbiterio propiamente y el transepto cuando éste queda bajo la zona de influencia del presbiterio como ocurre en nuestro caso -Iglesia Catedral de Santa María la Real de la Almudena-), lo normal es que la pareja no se separe (...) éste (el consorte) se situará a continuación de su respectivo esposo o esposa" (FUENTE LAFUENTE, C. 2011:183). Todos ellos además de estar ordenados según la precedencia de la diócesis a la que pertenecen, se ordenaran entre ellos según el orden interno considerado en cada una de ellas, orden que atenderá exclusivamente a la posición jerárquica de la jurisdicción que ostenten. Se distinguirán los unos de los otros porque en la solapa izquierda lucirán la insignia de la diócesis de origen, y sabremos quienes son los consortes porque no lucirán insignia alguna. Para todos ellos quedarán reservadas las primeras dieciséis filas de los bancos centrales. De todos modos, les será facilitada una lista detallada que contendrá el nombre y tratamiento, el cargo, la Curia de procedencia y la ubicación exacta para cada uno de ellos. Para ayudarles con la identificación se les incluirá un documento con el orden de precedencias de las diócesis de España, incluida la CEE.

Seguidamente encontrarán a las autoridades civiles y militares que ocuparán las siguientes diez filas de bancos. Tras éstos, los otros invitados de renombre, los cuales ocuparán las subsiguientes cuatro filas de bancos. De ambos grupos, también llegado el día, se les hará entrega de la lista detallada que contendrá ubicación exacta para cada uno de ellos e incluirá todos los detalles.

\footnotetext{
${ }^{5}$ Serán aquellos laicos que forman parte de las Curias de España, entendiendo por Curia el equipo de gobierno de una diócesis, por tanto, serán laicos sobre los que pesará un mandato que implicará una determinada jurisdicción sobre uno o varios aspectos del gobierno de la diócesis.
} 
Por último, se situarán el resto de los laicos que habiendo expresado el deseo de asistir al acto, hayan recibido la gracia de ser invitados. Para éstos se reservarán las restantes filas de bancos de la nave central, sumando éstas un total de seis

Tras la celebración de la Santa Misa se servirá un cóctel de bienvenida en las dependencias del Arzobispado de Madrid, edificio contiguo a esta Iglesia Catedral. Ubicación que queda detallada en la Figura B. que se les adjunta. 
Figura C.

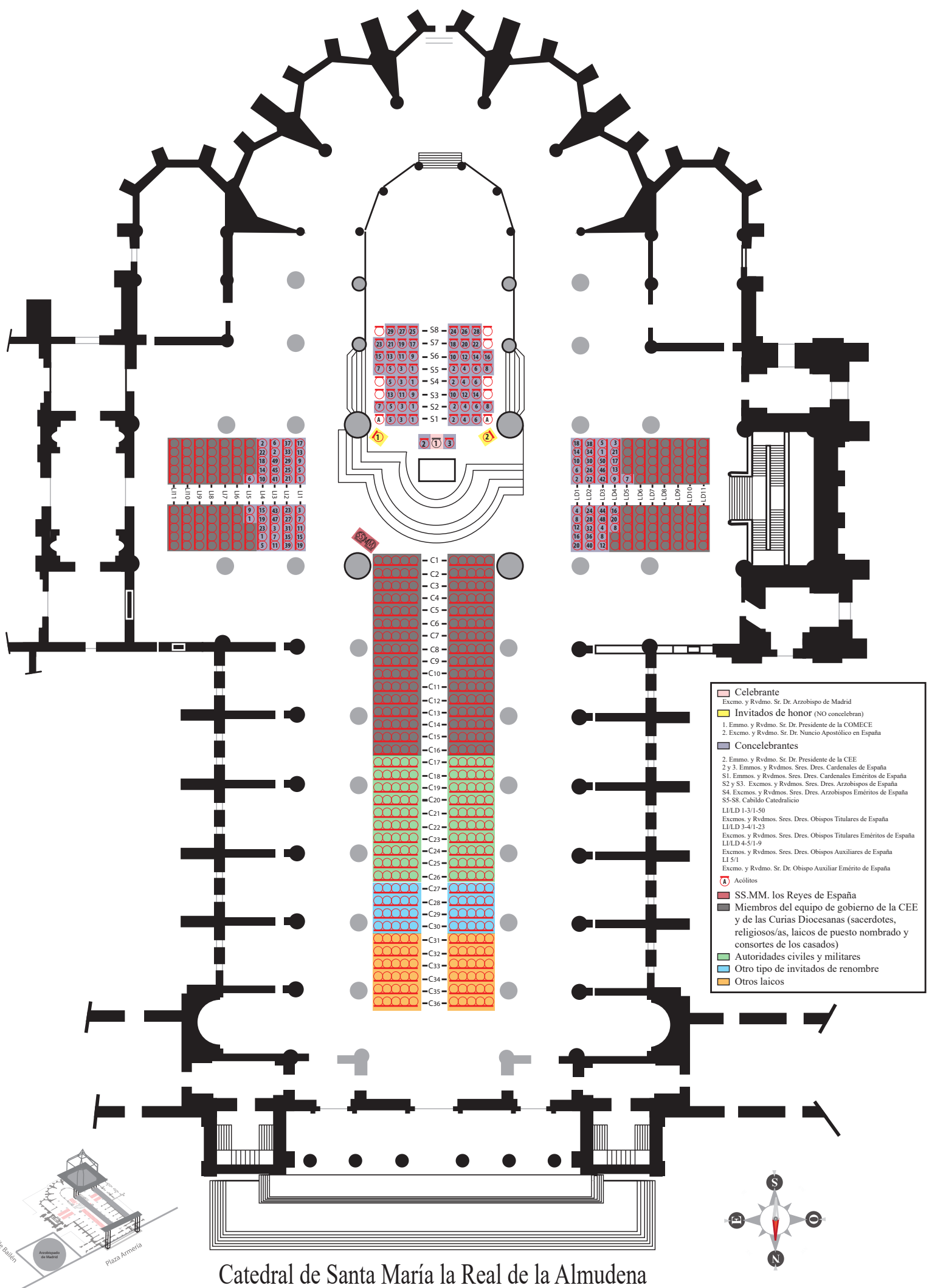


COMUNICADO DE PRENSA PARA LA FIGURA C.

La visita oficial del Presidente de la Comisión de los Episcopados de la Comunidad Europea a la Conferencia Episcopal Española se iniciará con la celebración de una misa solemne en la Iglesia Catedral de Santa María la Real de la Almudena

La CEE acoge la visita oficial del Presidente de la COMECE

La Conferencia Episcopal Española (CEE) tiene el gusto de acoger en visita oficial del $\mathrm{X}$ al $\mathrm{Y}$ del mes próximo al Presidente de la COMisión de los Episcopados de la Comunidad Europea (COMECE), Emmo. y Rvdmo. Sr. Dr. D. XX

El recibimiento oficial tendrá lugar en la Iglesia Catedral de Santa María la Real de la Almudena con la celebración de una misa solemne que contará con la participación de todas las Curias de España.

La CEE recibe la visita oficial del Presidente de la COMECE. El recibimiento oficial tendrá lugar en la Iglesia Catedral de Santa María la Real de la Almudena el próximo día XX del mes YY. La celebración se iniciará a las 18 h00. Será presidida por el Obispo de Madrid, Excmo. Y Rvdmo. Sr. Dr. D. XX con la participación de todas las Curias de España y así mismo, contará con la asistencia de SS.MM. los Reyes de España y del Nuncio Apostólico en España. Tras la celebración de la Santa Misa será ofrecido un cóctel de bienvenida en los salones del edificio del Arzobispado de Madrid, situado contiguo al edificio de la Iglesia Catedral.

Como pueden ver en la Figura C. que se les adjunta, la disposición de los participantes será la siguiente y responderá a la actualidad de los tiempos:

La celebración será presidida por el Obispo de Madrid, Excmo. y Rvdmo. Sr. Dr. D. XX, en calidad de titular de esta sede obispal, ya que es el obispo del lugar el designado para presidir las celebraciones en su casa, aunque en este caso el anfitrión propiamente no sea él, sino la $\mathrm{CEE}^{6}$. Por tanto, a su derecha (izquierda para el

\footnotetext{
${ }^{6}$ El obispo que se encuentra en su sede episcopal tiene potestad jurídica sobre la misma, por lo tanto es su máxima autoridad, no teniendo porque ceder la presidencia salvo si concurriese con una autoridad superior. No siendo éste el caso, es el obispo quien preside ya que el Presidente de la CEE representa a un órgano colegiado y no a sí mismo.
} 
espectador) y en calidad de concelebrante (al que a efectos puramente prácticos, podríamos llamar "concelebrante primero" pues es el anfitrión del visitante en honor del cual se ha organizado esta celebración) se encontrará el Presidente de la CEE, Emmo. y Rvdmo. Sr. Dr. D. XX y a la izquierda (derecha para el espectador) también como concelebrante se encontrará el otro cardenal no emérito de España: el Emmo. y Rvdmo. Sr. Dr. D. XX. También en la parte principal del presbiterio se encontrarán dos de los tres invitados de honor. No estarán revestidos y por tanto no actuarán como concelebrantes. El Obispo de Madrid tendrá a su derecha (izquierda para el espectador) el principal invitado de honor, el Emmo. y Rvdmo. Sr. Dr. D. XX, Presidente de la COMECE y a su izquierda (derecha para el espectador) otro de los invitados de honor, el Nuncio Apostólico en España, Excmo. y Rvdmo. Sr. Dr. D. XX.

En la parte trasera del presbiterio, zona donde se sitúa el cabildo de esta Iglesia Catedral, se encontrarán sentados, según el orden descrito en la Figura C.: los Emmos. y Rvdmos. Sres. Dres. Cardenales Eméritos de España; los Excmos. y Rvdmos. Sres. Dres. Arzobispos de España; los Excmos. y Rvdmos. Arzobispos Eméritos de España; tras todos ellos, el Cabildo Catedralicio de ésta. Todos revestidos, pues actuarán como concelebrantes en el oficio.

En la parte baja del altar mayor, ya fuera del presbiterio (zona reservada para los ordenados), podrán ver a SS.MM. los Reyes de España como invitados de honor, por tanto, sus sillones se encontrarán en lugar separado y preminente y a la derecha del celebrante (izquierda para el espectador). También en esta zona, ocupando la parte delantera de las cuatro hileras de los bancos laterales y todos revestidos, se encontrarán, según la ordenación establecida en la Figura C., el resto de los concelebrantes. En los asientos vacantes de esta zona, tras los que figuran numerados y nombrados en el cuadro de correlaciones de la Figura C., se situarán los restantes miembros de las Curias de España: sacerdotes, ataviados con traje clergyman -pues no participarán como concelebrantes- y con el alfiler con la insignia de su diócesis sobre la solapa izquierda del traje; religiosos/as ataviados según el hábito que les correspondiese o con traje oscuro los señores y traje corto las señoras, igualmente lucirán sobre el lado superior izquierdo de la indumentaria el alfiler con la insignia de su diócesis seguido del de la insignia de la comunidad a la que pertenecen; los laicos de 
puesto nombrado ${ }^{7}$, ataviados igualmente con traje oscuro los señores y traje corto las señoras, y alfiler con la insignia de la diócesis a la que pertenecen sobre la solapa izquierda. Las precedencias para los miembros de las diferentes Curias vendrá definido en primer lugar por la precedencia en sí de una diócesis respecto a otra y en segundo lugar se ordenarán entre ellos (ya sean sacerdotes, religiosos/as o laicos) según el orden interno considerado en cada una de ellas, el cual atenderá exclusivamente a la posición jerárquica de la jurisdicción que ostenten. De todos modos, el orden de precedencias exacto se les entregará llegado el día. Será una lista detallada que contendrá el nombre y tratamiento, cargo, Curia de procedencia y ubicación exacta para cada uno de ellos. Para ayudarles con la identificación se les incluirá un documento con el orden de precedencias de las diócesis de España, incluida la CEE. Nótese que en este caso los cónyuges de los laicos no se encontrarán junto a ellos puesto que en esta distribución habrá laicos que se encuentren todavía situados en el transepto -zona de influencia del altar mayor-, que en nuestro caso representa la "zona de presidencia" ${ }^{8}$. Así pues, los cónyuges de los laicos de puesto nombrado serán colocados todos juntos en los últimos bancos de la fila central de la zona reservada todavía para los miembros de las Curias, justo antes de los reservados a las autoridades civiles y militares, y se situarán respetando el mismo orden de precedencia que le haya sido asignado a su respectivo esposo o esposa, según sea el caso.

Seguidamente encontrarán a las autoridades civiles y militares que ocuparán las siguientes diez filas de bancos. Tras éstos, los otros invitados de renombre, los cuales ocuparán las subsiguientes cuatro filas de bancos. De ambos grupos, también llegado el día, se les hará entrega de la lista detallada que contendrá ubicación exacta para cada uno de ellos e incluirá todos los detalles.

\footnotetext{
${ }^{7}$ Serán aquellos laicos que forman parte de las Curias de España, entendiendo por Curia el equipo de gobierno de una diócesis, por tanto, serán laicos sobre los que pesará un mandato que implicará una determinada jurisdicción sobre uno o varios aspectos del gobierno de la diócesis.

8 "En los actos públicos institucionales (...), los consortes no se colocan en la presidencia (...). Normalmente, a los consortes se les procura un lugar especial, a ser posible, al margen de las autoridades." (FUENTE LAFUENTE, C. 2011:182).
} 
Por último, se situarán el resto de los laicos que habiendo expresado el deseo de asistir al acto, hayan recibido la gracia de ser invitados. Para éstos se reservarán las restantes filas de bancos de la nave central, sumando éstas un total de seis.

Tras la celebración de la Santa Misa se servirá un cóctel de bienvenida en las dependencias del Arzobispado de Madrid, edificio contiguo a esta Iglesia Catedral. Ubicación que queda detallada en la Figura C. que se les adjunta.

\section{ORDEN DE PRECEDENCIAS DE LAS DIÓCESIS ESPAÑOLAS (incluida CEE) A FECHA 3 DE ABRIL DE 2016}

0. CEE (Conferencia Episcopal Española)

1. Diócesis de Valencia

2. Diócesis de Valladolid

3. Diócesis de Santiago de Compostela

4. Diócesis de Granada

5. Diócesis de Tarragona

6. Diócesis de Pamplona y Tudela

7. Arzobispado Castrense de España

8. Diócesis de Sevilla

9. Diócesis de Toledo

10. Diócesis de Oviedo

11. Diócesis de Urgell

12. Diócesis de Mérida-Badajoz

13. Diócesis de Madrid

14. Diócesis de Zaragoza

15. Diócesis de Burgos
16. Diócesis de Barcelona

17. Diócesis de Huelva

18. Diócesis de Ciudad Real

19. Diócesis de Albacete

20. Diócesis de Mallorca

21. Diócesis de Canarias

22. Diócesis de Salamanca

23. Diócesis de León

24. Diócesis de Sigüenza-Guadalajara

25. Diócesis de Alcalá de Henares

26. Diócesis de Málaga

27. Diócesis de Orihuela-Alicante

28. Diócesis de Segovia

29. Diócesis de Jaén

30. Diócesis de Almería

31. Diócesis de Sant Feliu de Llobregat 
32. Diócesis de Ávila

33. Diócesis de Tui-Vigo

34. Diócesis de Segorbe-Castellón

35. Diócesis de Getafe

36. Diócesis de Terrassa

37. Diócesis de Plasencia

38. Diócesis de Vic

39. Diócesis de Cartagena

40. Diócesis de Tortosa

41. Diócesis de Córdoba

42. Diócesis de Ibiza

43. Diócesis de Ciudad Rodrigo

44. Diócesis de Santander

45. Diócesis de Lleida

46. Diócesis de Tenerife

47. Diócesis de Cuenca

48. Diócesis de Cádiz y Ceuta

49. Diócesis de San Sebastián

50. Diócesis de Zamora

51. Diócesis de Coria-Cáceres
52. Diócesis de Lugo

53. Diócesis de Bilbao

54. Diócesis de Osma-Soria

55. Diócesis de Girona

56. Diócesis de Jerez de la Frontera

57. Diócesis de Guadix

58. Diócesis de Teruel y Albarracín

59. Diócesis de Solsona

60. Diócesis de Huesca

61. Diócesis de Jaca

62. Diócesis de Tarazona

63. Diócesis de Orense

64. Diócesis de Astorga

65. Diócesis de Barbastro-Monzón

66. Diócesis de Vitoria

67. Diócesis de Mondoñedo-Ferrol

68. Diócesis de Calahorra y La CalzadaLogroño

69. Diócesis de Menorca

70. Diócesis de Palencia 
- Estupendo Faustina, ya casi hemos terminado, sólo una cosita más para poder avalar, de algún modo, ante su Excelencia el exceso de libertades que me he tomado proponiendo ordenaciones jamás usadas.

- Cómo no, Don Proti, dígame qué más puedo hacer por usted y lo haré de mil amores.

- Muy sencillo, voy a dictarle un último documento con unas cuantas referencias de textos oficiales que me valgan de apoyo para paliar tal osadía.

- Vamos a ello que el tiempo es oro, y su Excelencia debe de estar ya impaciente por que usted le entregue el boceto de ordenaciones que le pidió antes de ayer.

- Le dicto, Faustina:

\section{REFERENCIAS DE TEXTOS OFICIALES DE APOYO PARA LA FIGURA Y EL COMUNICADO B. $Y$ PARA LA FIGURA Y EL COMUNICADO C.}

La reflexión para proponer ordenaciones diferentes (Figura B. y Figura C.) a la habitualmente usada (Figura A.) ha sido fruto de la lectura detenida de los textos que citan a continuación. Los cuales, de algún modo, avalarían la osadía de ubicar a los laicos de puesto nombrado en sitios de preferencia, lo que haría que pudieran ser identificados perfectamente. Como consecuencia, lo que la Iglesia estaría comunicando a luz pública, pues a nivel privado se da ya desde la finalización y puesta en práctica de los documentos emitidos por el Concilio Vaticano II, sería que ya no es una Iglesia puramente clerical, sino que dentro de la misma tienen cabida los laicos como plenos miembros del Pueblo de Dios, ya que en su correcta acepción "Pueblo de Dios" son todos los incorporados a Cristo por el bautismo:

“C.204 § 1. Son fieles cristianos quienes, incorporados a Cristo por el bautismo, se integran en el pueblo de Dios, y hechos partícipes a su modo por esta razón de la función sacerdotal, profética y real de Cristo, cada uno según su propia condición, son llamados a desempeñar la misión que Dios encomendó cumplir a la Iglesia en el mundo." (Código de Derecho Canónico, 1983). 
Así pues, si me lo permite su Excelencia, me gustaría que cuando lea los borradores para los comunicados de prensa que ha producido mi atrevimiento (Comunicado de Prensa para la Figura B. y Comunicado de Prensa para la Figura C.), haga su mente memoria de los artículos que a continuación le cito y apiádese de mí, que falto de humildad me he permitido el extralimitarme en mis funciones.

\section{De los documentos emitidos por el Concilio Vaticano II:}

\section{De la Constitución Dogmática "Lumen Gentium":}

“32. Por designio divino, la santa Iglesia está organizada y se gobierna sobre la base de una admirable variedad. "Pues a la manera que en un solo cuerpo tenemos muchos miembros, y todos los miembros no tienen la misma función, así nosotros, siendo muchos, somos un solo cuerpo en Cristo, pero cada miembro está al servicio de los otros miembros» (Rm 12,4-5).

Por tanto, el Pueblo de Dios, por Él elegido, es uno: "un Señor, una fe, un bautismo» (Ef 4,5). Es común la dignidad de los miembros, que deriva de su regeneración en Cristo; común la gracia de la filiación; común la llamada a la perfección: una sola salvación, única la esperanza e indivisa la caridad. No hay, de consiguiente, en Cristo y en la Iglesia ninguna desigualdad por razón de la raza o de la nacionalidad, de la condición social o del sexo, porque "no hay judío ni griego, no hay siervo o libre, no hay varón ni mujer. Pues todos vosotros sois "uno" en Cristo Jesús» (Ga 3,28 gr.; cf. Col 3,11).

(...) Aun cuando algunos, por voluntad de Cristo, han sido constituidos doctores, dispensadores de los misterios y pastores para los demás, existe una auténtica igualdad entre todos en cuanto a la dignidad y a la acción común a todos los fieles en orden a la edificación del Cuerpo de Cristo. Pues la distinción que el Señor estableció entre los sagrados ministros y el resto del Pueblo de Dios lleva consigo la solidaridad, ya que los Pastores y los demás fieles están vinculados entre sí por recíproca necesidad. Los Pastores de la Iglesia, siguiendo el ejemplo del Señor, pónganse al servicio los unos de los otros y al de los restantes fieles; éstos, a su vez, asocien gozosamente su trabajo al de los Pastores y doctores. De esta manera, todos rendirán un múltiple testimonio de admirable unidad en el Cuerpo de Cristo. 
Pues la misma diversidad de gracias, servicio y funciones congrega en la unidad a los hijos de Dios, porque "todas... estas cosas son obra del único e idéntico Espíritu» (1 Co 12,11)."

“33. (...)

Además de este apostolado, que incumbe absolutamente a todos los cristianos, los laicos también puede ser llamados de diversos modos a una colaboración más inmediata con el apostolado de la Jerarquía [114 Cf. Pío XII. aloc. Six ans se sont écoulés, 5 oct. 1957: AAS 49 (1957) 927], al igual que aquellos hombres y mujeres que ayudaban al apóstol Pablo en la evangelización, trabajando mucho en el Señor (cf. Flp 4,3; Rm 16,3ss). Por lo demás, poseen aptitud de ser asumidos por la Jerarquía para ciertos cargos eclesiásticos, que habrán de desempeñar con una finalidad espiritual."

\section{Del Decreto "Ad Gentes Divinitus":}

"21. La Iglesia no está verdaderamente fundada, ni vive plenamente, ni es signo perfecto de Cristo entre las gentes, mientras no exista y trabaje con la Jerarquía un laicado propiamente dicho. Porque el Evangelio no puede penetrar profundamente en la mentalidad, en la vida y en el trabajo de un pueblo sin la presencia activa de los laicos. Por tanto, desde la fundación de la Iglesia hay que atender, sobre todo, a la constitución de un laicado cristiano maduro."

\section{Del Decreto "Christus Dominus":}

"27. (...)

Los sacerdotes y seglares que pertenecen a la curia diocesana sepan que prestan su ayuda al ministerio pastoral del Obispo."

Del Código de Derecho Canónico (1983) -además del ya citado C.204 § 1.-:

“C.129 § 1. De la potestad de régimen, que existe en la Iglesia por institución divina, y que se llama también potestad de jurisdicción, son sujetos hábiles, conforme a la norma de las prescripciones del derecho, los sellados por el orden sagrado. 
$\S 2$. En el ejercicio de dicha potestad, los fieles laicos pueden cooperar a tenor del derecho."

"C.146 Un oficio eclesiástico no puede obtenerse válidamente sin provisión canónica."

“C.147 La provisión de un oficio se hace mediante libre colación por la autoridad eclesiástica competente; por institución de ésta cuando haya precedido presentación; por confirmación o admisión por la misma cuando ha precedido elección o postulación; finalmente, por simple elección y aceptación del elegido cuando la elección no necesita ser confirmada."

"C.148 La provisión de los oficios compete a la misma autoridad a quien corresponde erigirlos, innovarlos o suprimirlos, a no ser que el derecho establezca otra cosa."

“C.149 \& 1. Para que alguien sea promovido a un oficio eclesiástico, debe estar en comunión con la Iglesia y ser idóneo, es decir, dotado de aquellas cualidades que para ese oficio se requieren por el derecho universal o particular, o por la ley de fundación."

“C.228 \& 1. Los laicos que sean considerados idóneos tienen capacidad de ser llamados por los sagrados Pastores para aquellos oficios eclesiásticos y encargos que pueden cumplir según las prescripciones del derecho.

$\S$ 2. Los laicos que se distinguen por su ciencia, prudencia e integridad tienen capacidad para ayudar como peritos y consejeros a los Pastores de la Iglesia, también formando parte de consejos, conforme a la norma del derecho."

“C.482 \& 1. En cada curia, debe haber un canciller, cuya principal función, a no ser que el derecho particular establezca otra cosa, consiste en cuidar de que se redacten las actas de la curia, se expidan y se custodien en el archivo de la misma."

“C.483 § 2. El canciller y los notarios deben ser personas de buena fama y por encima de toda sospecha; en las causas en las que pueda ponerse en juicio la buena fama de un sacerdote, el notario debe ser sacerdote." (De este canon se deduce que no es necesario que el canciller, miembro obligado en una curia, tenga que ser siempre una 
persona que haya recibido el orden sacerdotal, por tanto, el cargo puede ser ocupado por un laico).

Por último, Excelencia, sólo una brevísima puntualización del porqué realicé una tercera ordenación (Figura C.), si con la segunda (Figura B.) ya quedaba recogido el pensamiento encerrado en los artículos que le acabo de mencionar. Pues bien, no fue otra la cosa que tratándose de una celebración de acogida por parte de la CEE al Presidente de la COMECE en visita oficial a ésta, me pareció que no era necesario que los no-consagrados bajo el orden episcopal tuvieran la necesidad de concelebrar, ya que para los actuales tiempos se me antojaba que quizá fuera mejor no sólo romper con la imagen clerical de la Iglesia, sino aprovechar también la ocasión para, podríamos decir si Usted me lo permite, colocar a los iguales con sus iguales: ordenados obispos: celebran, ya que se trata de un órgano episcopal, la COMECE, que visita oficialmente a otro órgano episcopal, la CEE; no ordenados obispos pero miembros de puesto nombrado de las diferentes Curias de España: comparten ubicación, ordenados según sus precedencias externas e internas y ataviados según su condición propia. Como sustento a esta humilde opinión, le brindo, Excelencia, el texto del canon en que la apoyé, en el sentido de que avala el hecho de que no todo sacerdote participante en una Eucaristía tiene la obligación de concelebrar la misma cuando no hacerlo pudiera ser de más utilidad.

"C.902 Pueden los sacerdotes concelebrar la Eucaristía, a no ser que la utilidad de los fieles requiera o aconseje otra cosa, permaneciendo, sin embargo, la libertad de cada uno para celebrar individualmente la Eucaristía, pero no mientras se está concelebrando en la misma iglesia u oratorio."

- Bueno Faustina, hemos terminado. Mil gracias por su ayuda. Y ahora, si es tan amable, prepáreme una copia en papel de cada uno de los documentos que me marcho corriendo a entregárselo su Excelencia. No quiero que se me haga más tarde que se me marchará a comer y estoy ansioso por dejar este asunto zanjado.

- Con gran placer, Don Proti. 
Unos minutos más tarde, Faustina le hizo entrega de los documentos a Don Proti y éste, tomándolos entre sus manos, salió presuroso hacia el despacho del Sr. Presidente.

- ¿Se puede Excelencia? Dijo Don Proti, mientras entreabría la puerta del despacho del Sr. Presidente.

- Adelante, ¿qué me trae de bueno?

- Excelencia, lo acordado, el borrador de la ordenación para la celebración de la misa solemne como acto de acogida al Sr. Presidente de la COMECE en su visita oficial a nuestra Santa Casa.

- Estupendo, pues déjelo aquí (señalando un ángulo de su mesa de trabajo) que esta tarde sin falta lo reviso y así, a lo más tardar mañana puede realizar la definitiva y enviarla a la prensa con el respectivo comunicado. ¿'Por cierto, me adjuntó también el borrador del comunicado de prensa?

- Por supuesto, ahí lo tiene todo.

- Muchísimas gracias, Don Proti, ino sabría qué hacer sin usted! Ahora, vaya con Dios que ya va siendo hora de irse a casa a comer. Y descuide, que mañana sin falta le digo algo, no quisiera que el tiempo se nos echase encima, ya me conoce, me gusta tener las cosas hechas con antelación suficiente.

- Sí, sí, cómo no, todo se hará según me indique.

- Hasta mañana, entonces. Tenga una buena tarde.

- Gracias, también para Usted.

Así fue como Don Proti puso el "broche de oro" a su carrera, entregando a su Excelencia las osadas propuestas sin darle más explicaciones y dejando a la libertad de éste el escoger una u otra. Tras ello, Don Proti se dio a la fuga. Nunca más se ha sabido nada de Don Proti ni de su paradero.

\section{¿iFIN!?}




\section{BIBLIOGRAFÍA}

\section{MANUALES:}

DENZINGER, H. (1963): El Magisterio de la Iglesia. Barcelona, Herder.

DENZINGER, H. y HÜNERMAN, P. (2000): El Magisterio de la Iglesia: Enchiridium Symbolorum Definitionume et Declarationum de Rebus Fidei et Morum. Barcelona, Herder.

ESCALERA AICUA, S. (2005): Ceremonial y protocolo religioso. Madrid, Ediciones Protocolo. FUENTE LAFUENTE, C. (2005): Manual práctico para la organización de eventos. Técnicas de organización de actos II. Madrid, Ediciones Protocolo.

FUENTE LAFUENTE, C. (2011): Protocolo para eventos. Técnicas de organización de actos I. Oviedo, Ediciones Protocolo.

SÁNCHEZ GONZÁLEZ, D. del M. (2011) Fundamentos del ceremonial y del protocolo. Madrid, Editorial Síntesis.

VV.AA. (1983): Código de Derecho Canónico. Promulgado por la Autoridad de Juan Pablo II, Papa. Dado en Roma, el día 25 de Enero de 1983. Edición digital procedente de la página oficial del Vaticano: http://www.vatican.va

\section{LIBROS:}

VILLEMIN, L. (2003) : Pouvoir d'ordre et de juridiction. Histoire théologique de leur distinction. Paris, Le Cerf.

\section{ARTÍCULOS:}

BORRAS, A. (2004) : "Ordre et juridiction: les enjeux théologiques actuels de l'histoire d'une distinction". En: Revue théologique de Louvain, no 35, pp. 495-509.

CHEVALIER, C. (2014) "Femmes en responsabilité pastorale en Belgique francophone. Un processus en cours d'institutionnalisation". En: Lumen Vitae, no 3, pp. 311-324.

\section{DOCUMENTOS:}

- Constitución Apostólica: "Sacrae Disciplinae Leges". En: Código de Derecho Canónico. Promulgado por la Autoridad de Juan Pablo II, Papa.

Dado en Roma, el dia 25 de Enero de 1983. Edición digital procedente de la página oficial del Vaticano: http://www.vatican.va

- Documentos del Concilio Vaticano II. Edición digital procedente de la página oficial del Vaticano: http://www.vatican.va

- Real Decreto 2099/1983, de 4 de Agosto, por el que se aprueba el Ordenamiento General de Precedencias del Estado. Edición digital del Boletín Oficial del Estado: http://boe.es

\section{PÁGINAS DIGITALES:}

Página oficial de la Conferencia Episcopal Española: http://www.conferenciaepiscopal.es Página oficial de la COMisión de Episcopados de la Comunidad Europea:

http://www.comece.org

Página oficial de cada una de las diócesis de España por orden alfabético:

Albacete: http://www.diocesisalbacete.org

Alcalá de Henares: http://www.obispadoalcala.org

Almería: http://www.diocesisalmeria.org

Astorga: http://www.diocesisastorga.es

Ávila: http://www.diocesisdeavila.com 
Barbastro-Monzón: http://www.diocesisbarbastromonzon.org

Barcelona: http://www.esglesiabarcelona.cat

Bilbao: http://www.bizkeliza.org

Burgos: http://www.archiburgos.es

Cádiz y Ceuta: http://www.obispadodecadizyceuta.org

Calahorra y La Calzada Logroño: http://www.iglesiaenlarioja.org

Canarias: http://www.diocesisdecanarias.org

Cartagena: http://www.diocesisdecartagena.org

Ciudad Real: http://www.diocesisciudadreal.es

Ciudad Rodrigo: http://www.diocesisciudadrodrigo.org

Córdoba: http://www.diocesisdecordoba.com

Coria-Cáceres: http://www.diocesiscoriacaceres.es

Cuenca: http://www.diocesisdecuenca.es

Getafe: http://www.diocesisgetafe.es

Girona: http://www.bisbatgirona.cat

Granada: http://www.diocesisgranada.es

Guadix: http://www.diocesisdeguadixbaza.org

Huelva: http://www.diocesisdehuelva.es

Huesca: http://www.diocesisdehuesca.org

Ibiza: http://www.obispadodeibiza.es

Jaca: http://www.diocesisdejaca.org

Jaén: http://www.diocesisdejaen.es

Jerez de la Frontera: http://www.diocesisdejerez.org

León: http://www.diocesisdeleon.org

Lleida: http://www.bisbatlleida.org

Lugo: http://www.diocesisdelugo.org

Madrid: http://www.archimadrid.org

Málaga: http://www.diocesismalaga.es

Mallorca: http://www.bisbatdemallorca.com

Menorca: http://www.bisbatdemenorca.com

Mérida-Badajoz: http://www.meridabadajoz.net

Mondoñedo-Ferrol: http://www.mondonedoferrol.org

Orense: http://www.obispadodeourense.com

Orihuela-Alicante: http://www.diocesisoa.org

Osma-Soria: http://www.osma-soria.org

Oviedo: http://www.iglesiadeasturias.org

Palencia: http://www.diocesispalencia.org

Pamplona y Tudela: http://www.iglesianavarra.org

Plasencia: http://www.diocesisplasencia.org

Salamanca: http://www.diocesisdesalamanca.com

San Sebastián: http://www.elizagipuzkoa.org

Sant Feliu de Llobregat: http://www.bisbatsantfeliu.cat

Santander: http://www.diocesisdesantander.com

Santiago de Compostela: http://www.archicompostela.org

Segorbe-Castellón: http://www.obsegorbecastellon.es

Segovia: http://www.obispadodesegovia.es/ 
Sevilla: http://www.archisevilla.org

Sigüenza-Guadalajara: http://www.siguenza-guadalajara.org

Solsona: http://www.bisbatsolsona.cat

Tarazona: http://www.diocesistarazona.org

Tarragona: http://www.arquebisbattarragona.cat

Tenerife: http://www.obispadodetenerife.es

Terrassa: http://www.bisbatdeterrassa.org

Teruel y Albarracín: http://www.diocesisdeteruel.org

Toledo: http://www.architoledo.org

Tortosa: http://www.bisbattortosa.org

Tui-Vigo: http://www.diocesetuivigo.org

Urgell: http://www.bisbaturgell.org

Valencia: http://www.archivalencia.org

Valladolid: http://www.archivalladolid.org

Vic: http://www.bisbatvic.com

Vitoria: http://www.diocesisvitoria.org

Zamora: http://www.diocesisdezamora.es

Zaragoza: http://www.arzobispadodezaragoza.org

Arzobispado Castrense de España: http://www.arzobispadocastrense.com

Página oficial de la Real Academia Española: http://www.rae.es

\section{PLANIMETRÍA:}

- HIDALGO GARCÍA, L. ${ }^{9}$ (2016). Realizadora del Diseño Gráfico Digital.

- Página oficial de la Iglesia Catedral de Santa María la Real de la Almudena: http://www.catedraldelaalmudena.es

- Planos de referencia de la Iglesia Catedral de Santa María la Real de la Almudena: https://www.google.be/search?q=plano+de+la+almudena\&biw $=1280 \& b i h=652 \&$ tbm $=i s c$ h\&tbo=u\&source=univ\&sa=X\&ei=GhR2VN2VFsjCOdqQgagG\&ved=0CCcQsAQ

- Vídeo de apoyo para la visualización de aforo y ubicaciones posibles en Iglesia Catedral de Santa María la Real de la Almudena: http://www.rtve.es/alacarta/videos/especialesinformativos/especial-informativo-funeral-estado-memoria-adolfo-suarez/2480672/

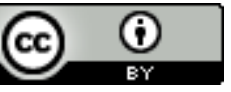

This work is licensed under a Creative Commons Attribution 3.0 Unported License

\footnotetext{
${ }^{9}$ Técnica Superior en Diseño y Producción Editorial (Premio Nacional en la familia de Artes Gráficas en 2010) y Graduada en Periodismo y Comunicación Audiovisual por la Universidad Carlos III, Madrid. laura.hidalgog@gmail.com
} 